\title{
PERANCANGAN DAN IMPLEMENTASI JARINGAN VOICE OVER INTERNET PROTOCOL (VoIP) PADA PT. NATIONAL LABEL
}

\author{
LIESNANINGSIH ${ }^{1)}$, ROHMAT TAUFIQ ${ }^{2)}, \&$ DERIL $^{3)}$ \\ Program Studi Informatika \\ Fakultas Teknik Universitas Muhammadiyah \\ Tangerang Jl. Perintis Kemerdekaan 1/33 Cikokol \\ Kota Tangerang \\ Email: liesnaningsih@gmail.com ${ }^{l)}$,rohmat.taufiq@umt.ac.id ${ }^{2}$, \\ dderil08@gmail.com ${ }^{3)}$
}

\begin{abstract}
ABSTRAK
Voice over Internet Protocol (VoIP) merupakan teknologi komunikasi suara berbasis IP, dimana user dapat melakukan komunikasi suara hanya dengan menggunakan jaringan internet, intranet, atau ethernet. PT National Label merupakan perusahaan swasta yang terus berkembang, sehingga membutuhkan sarana komunikasi yang baik untuk menunjang produktifitas perusahaan. Saat ini PT National Label sudah menerapkan telepon PABX sebagai sarana komunikasi. Mahalnya harga telepon PABX dapat mengakibatkan meningkatnya biaya operasional perusahaan, sehingga dengan dirancang dan diimplentasikannya VoIP dapat menjadi alternatif solusi dari permasalahan tersebut. Jaringan VoIP yang dirancang menggunakan server CentOS sehingga menjadi sistem Trixbox $C E$ berbasis SIP (Session Initiation Protocol). Dengan menggunakan infrastruktur jaringan nirkabel seperti wifi, teknologi VoIP dapat digunakan pada telepon jaringan atau diperangkat mobile dengan menggunakan softphone seperti aplikasi mobile $X$-Lite dan Zoiper sebagai pengganti IP Phone yang terhubung dengan satu jaringan. Diharapkan dengan adanya teknologi VoIP di PT National Label dapat memberikan manfaat bagi karyawan dalam menunjang sarana komunikasi via internet tanpa mengeluarkan biaya yang besar.
\end{abstract}

Kata Kunci: Jaringan, Internet, Server, VoIP.

\section{PENDAHULUAN}

Pemanfaatan teknologi informasi sebagai media komunikasi telah banyak digunakan berbagai organisasi, perusahaan, atau instansiinstansi lain untuk menunjang kegiatan-kegiatan yang membutuhkan komunikasi. Voice over Internet Protocol (VoIP) merupakan teknologi komunikasi suara berbasis IP, dimana user dapat melakukan komunikasi suara hanya dengan menggunakan jaringan internet, intranet, atau ethernet.

Teknologi VoIP telah banyak diterapkan karena rendahnya biaya untuk melakukan komunikasi antar ruang tanpa dibatasi oleh jarak, akan tetapi VoIP yang diterapkan pada perusahaan saat ini belum bersifat fleksibel dan mobile, jika pengguna ingin menggunakan teknologi ini mereka harus berada pada meja kerjanya, maka apabila ada pangilan yang ber- sifat penting dan pengguna tidak berada pada meja kerjanya, hal ini dapat menurunkan produktifitas perusahaan.

Dengan infrastruktur jaringan nirkabel, teknologi VoIP dapat digunakan pada telepon jaringan atau perangkat mobile dengan menggunakan softphone seperti aplikasi mobile Xlite dan Zoiper sebagai pengganti IP phone yang terhubung dengan satu jaringan. X-lite dan Zoiper adalah aplikasi softphone yang dapat diinstal pada perangkat mobile untuk mensimulasikan aksi telepon seperti membuat, menerima, dan mengelola panggilan suara melalui internet.

PT National Label saat ini sudah menerapkan telepon PABX sebagai sarana komunikasi, tetapi seiring berkembangnya PT National Label maka semakin banyak pengguna yang memerlukan media komunikasi, sedang- 
kan mahalnya harga telepon PABX dapat mengakibatkan meningkatnya biaya operasional perusahaan, sehingga perusahaan harus mencari alternatif lain agar komunikasi antar ruangan tidak terhambat dan tidak menurunkan produktifitas perusahaan.

Dengan dirancang dan diimplementasikannya VoIP diharapkan dapat menjadi alternatif solusi untuk meminimalisir biaya opersional perusahaan. Jaringan VoIP yang dirancang menggunakan server CentOS sehingga menjadi sistem Trixbox CE, aplikasi yang memungkinkan pengguna mengimplementasikan layanan VoIP, membangun sentral telepon sendiri yang bisa digunakan sebagai telepon jaringan dan perangkat mobile seperti smartphone dan laptop, agar pengguna yang sedang tidak berada di tempat bekerja tetapi ingin menggunakan VoIP cukup menggunakan jaringan nirkabel dengan SIP (Session Initiation Protocol)

Adapun tujuan penelitian adalah: 1) Merancang jaringan Voice Over Internet Protocol di PT.National Label; 2) Membantu pihak PT.National Label untuk mengembangkan sistem komunikasi alternatif guna menunjang kebutuhan komunikasi antar karyawan dan membantu program penghematan perusahaan; dan 3). Mengimplemen-tasikan jaringan Voice over Internet Protocol yang sudah dibuat ke PT. National Label.

\section{TINJAUAN PUSTAKA}

\section{Pengertian Perancangan}

Pengertian perancangan menurut Ladjamudin, Perancangan adalah tahapan perancangan memiliki tujuan untuk mendesignsistem baru yang dapat menyelesaikan masalah-masalah yang dihadapi perusahaan yang diperoleh dari pemilihan alternatif sistem yang terbaik (Taufiq, 2016).

\section{Pengertian Jaringan}

Menurut Azhar (2018:37), jaringan adalah sebuah sistem yang terdiri atas komputer, software, dan perangkat jaringan lainnya yang bekerja bersama-sama untuk mencapai suatu tujuan yang sama. Secara lebih sederhana, jaringan komputer dapat diartikan sebagai sekumpulan komputer beserta mekanisme dan prosedurnya yang saling terhubung dan berkomunikasi. Komunikasi yang dilakukan oleh komputer tersebut dapat berupa transfer berbagai data, instruksi, dan informasi dari satu komputer ke komputer lain.

\section{Pengertian VoIP (Voice over Internet Protocol)}

Menurut Riswandha (2013:16) dalam bahasa yang sederhana VoIP adalah teknik untuk bertelepon di atas jaringan internet, teknologi yang dikembangkan memungkinkan untuk membangun sentral telepon sendiri hingga pesawat teleponnya.

\section{Pengertian Softphone}

Menurut Yuniati, dkk (2014:115), Softphone adalah perangkat lunak yang mensimulasikan aksi telepon dan memungkinkan Anda membuat, menerima dan mengelola panggilan suara melalui Internet. Softphone biasanya berjalan di komputer, tablet, PC, dan smartphone, dan diperlukan untuk melakukan panggilan VoIP (Voice over IP) dan panggilan video.

1. X-Lite

Softphone X-Lite merupakan software yang diinstall pada komputer dengan fungsi dapat melakukan panggilan telepon melalui Briker IPPBX layaknya telepon atau IP Phone.

2. Zoiper

Zoiper adalah softphone VoIP yang memungkinkan Anda membuat chatting atau membuat panggilan suara dan video dengan teman, keluarga, kolega dan mitra bisnis (anonim, 2018). Tidak seperti software lain seperti Skype atau Viber, terbuka dan dapat digunakan dengan penyedia VoIP atau PBX.

\section{METODELOGI PENELITIAN}

Jenis penelitian yang digunakan dalam proses penulisan ini adalah Studi Kasus (Case Study Research) yang merupakan serangkaian kegiatan ilmiah yang dilakukan secara intensif, terinci, dan mendalam tentang suatu program, peristiwa, dan aktivitas, baik pada tingkat perorangan, sekelompok orang, lembaga, atau organisasi untuk memperoleh pengetahuan mendalam tentang peristiwa tersebut dalam jangka waktu tertentu dan mengumpulkan data dari berbagai sumber (observasi, dokumen, laporan, atau wawancara).

Dalam mengumpulkan data primer, penulis menggunakan beberapa metode yaitu:

1. Metode observasi, dilakukan secara langsung di PT.National Label dari tanggal 02 Mei 2019 s/d 17 Mei 2019, Melakukan pengamatan objek tentang alat komunikasi yang digunakan kar- 
yawan dan mengamati infrastruktur jaringan yang diterapkan dilokasi, sehingga tidak terjadinya kendala ketika melakukan impelementasi.

2. Metode wawancara, dilakukan secara langsung dengan pihak yang terkait untuk memperoleh informasi tentang infrastruktur jaringan yang berjalan pada PT. National Label, melakukan wawancara kepada 2 departemen terkait, yakni departemen IT dan GA/HRD.

\section{HASIL PENELITIAN}

\section{Skema Jaringan Berjalan}

Skema telepon berjalan, yaitu memprogram PABX Panasonic type TDA dengan menggunakan digital key telephone pada TDA jumlah yang bisa terpasang tergantung dari card, tidak semua line ini bisa dipakai tergantung pada providernya.

Skema telepon berjalan bersifat intercom atau local area sehingga tidak bisa menelepon ke handphone yang menyebabkan komunikasi terbatas.

Topologi jaringan yang digunakan di PT. National Label menggunakan lebih dari satu topologi jaringan atau sering kita sebut dengan topologi Hybrid karena menyesuaikan dengan lokasi penempatan client yang ada.

Arsitektur jaringan yang digunakan di PT. National Label adalah dengan jaringan Client Server. Maka dalam proses pembagian aplikasi dibagi menjadi dua secara terpisah, akan tetapi masih dalam satu jaringan yang berfungsi sebagai client dan server.

\section{Perancangan Jaringan Usulan}

1) Skema Jaringan VoIP

Berikut adalah skema jaringan VoIP yang diusulkan pada PT.National Label dengan menggunakan VirtualBox Grafhical User Iterface Version 5.2.28 r130011(Qt5.6.2) sebagai server virtual Trixbox version 2.8.0.4

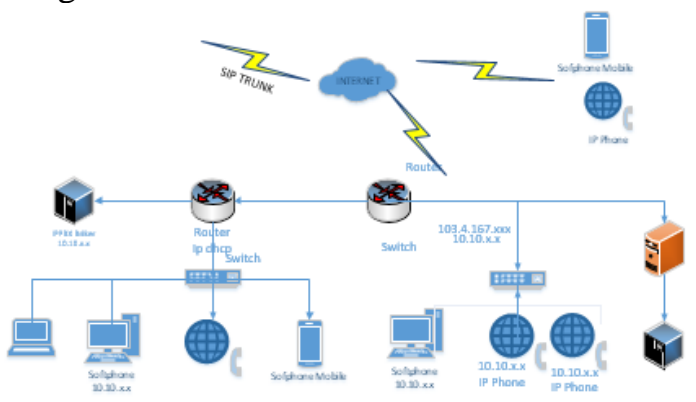

Gambar 1. Skema jaringan VoIP yang diusulkan

Ada beberapa rancangan aplikasi atau peralatan pendukung software yang dibutuhkan diantaranya:

a) VirtualBox Grafhical User Iterface Version 5.2.28 r130011(Qt5.6.2) sebagai server virtual Trixbox version 2.8.0.4

b) Cent OS Version 5.5 (final)

c) Softphone X-Lite dan Zoiper yang terpasang di perangkat mobile seperti PC, laptop dan smartphone.

2) Manajemen Jaringan VoIP

Untuk dapat berkomunikasi antara satu user dengan user yang lainnya, tentunya dibutuhkan sebuah device, seperti pesawat telepon, dengan sistem CentOS ini setiap user diharuskan memiliki IP phone, karena harga sebuah IP phone cukup mahal, maka disini kami memberikan solusi dengan menggunakan IP softphone yang bernama X-lite dan Zoiper yang dapat kita download secara gratis. Pada proses perancangan pada sisi client, ada beberapa tahap perancangan yang harus dilakukan. Tahapan-tahapan tersebut dapat dilihat pada flowchart berikut:

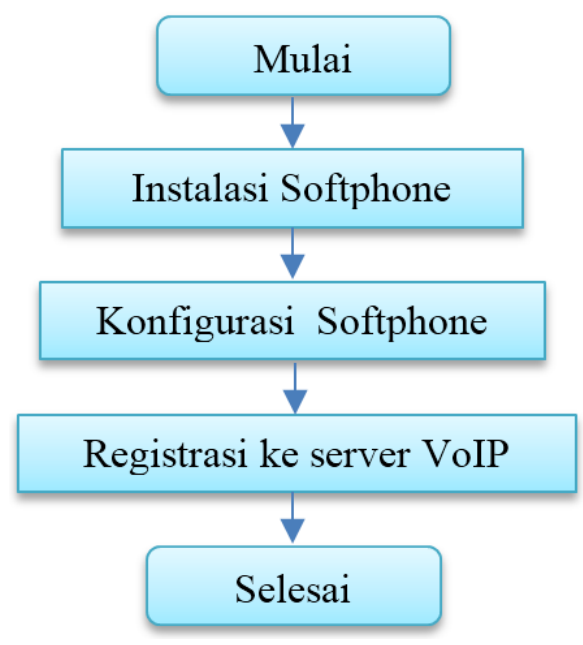

Gambar 2. Flowchart Tahapan Konfigurasi Softphone

3) Pengujian Jaringan

a) Pengujian pada sisi server

Tabel 1. Pengujian server Trixbox

\begin{tabular}{|c|l|l|l|}
\hline No & Nama Pengujian & Indikator Pengujian & Status Pengujian \\
\hline 1 & $\begin{array}{l}\text { Komputer server } \\
\text { booting dengan } \\
\text { normal. }\end{array}$ & $\begin{array}{l}\text { Muncul halaman } \\
\text { login pada layar } \\
\text { monitor. }\end{array}$ & $\begin{array}{l}\text { Muncul halaman } \\
\text { login. }\end{array}$ \\
\hline 2 & $\begin{array}{l}\text { Komputer server } \\
\text { dapat dikonfigurasi } \\
\text { melalui web base. }\end{array}$ & $\begin{array}{l}\text { Muncul tampilan } \\
\text { pada web browser } \\
\text { halaman Tricbox user } \\
\text { mode. }\end{array}$ & $\begin{array}{l}\text { Muncul halaman } \\
\text { Trixbox user mode. }\end{array}$ \\
\hline
\end{tabular}


b) Pengujian pada sisi client

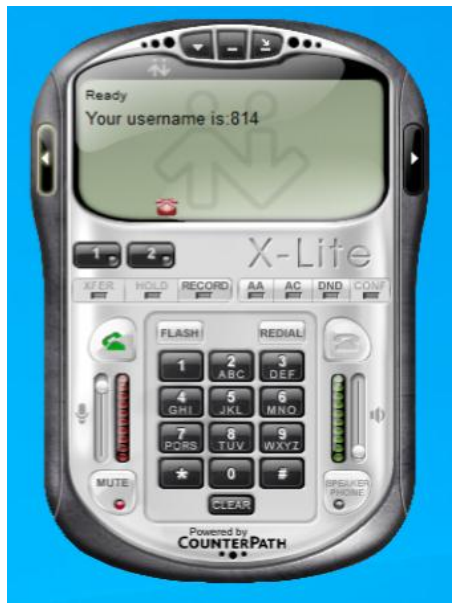

Gambar 3. Tampilan client VoIP yang sudah teregistrasi pada laptop

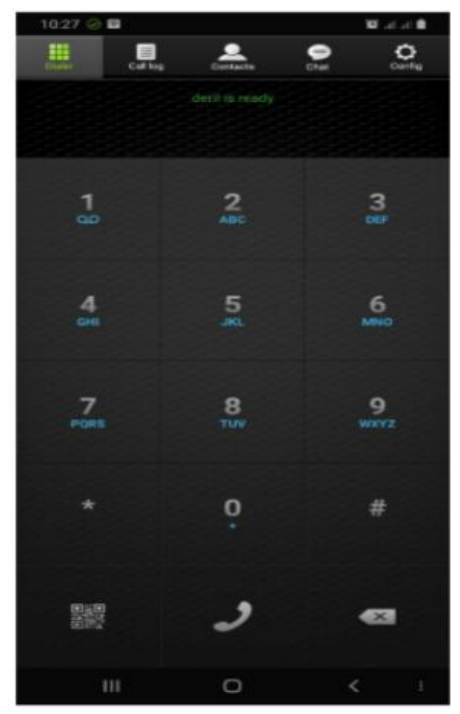

Gambar 4. Client yang sudah terregistrasi di smartphone

c) Pengujian antar client

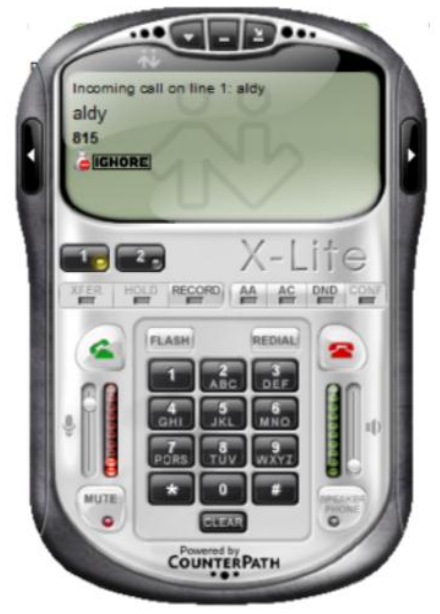

Gambar 5. Kotak dialog panggilan masuk X-lite

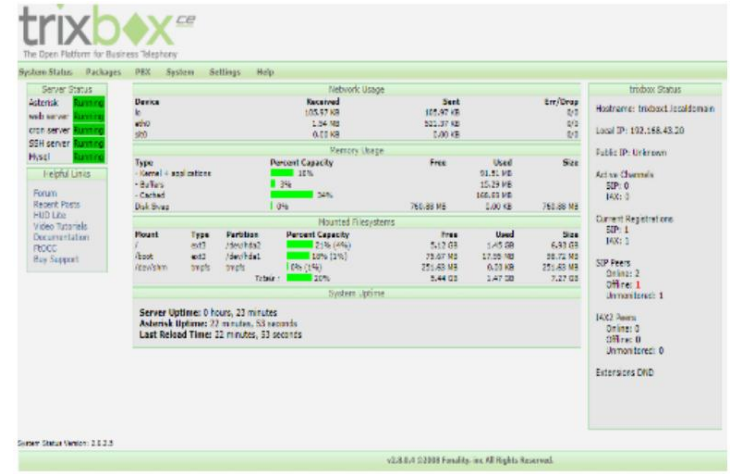

Gambar 6. Hasil capture aktifitas user.

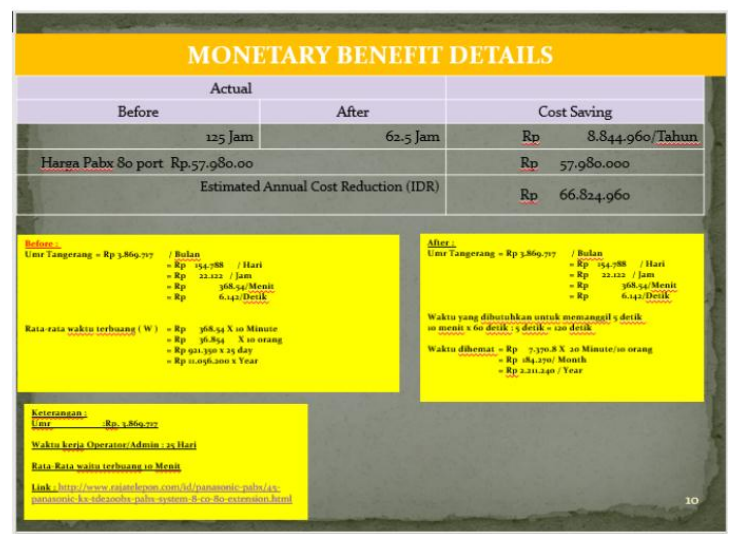

Gambar 7. Benefit Details

\section{KESIMPULAN}

Dari pembahasan yang sudah dijabarkan maka dapat disimpulkan beberapa hal sebagai berikut:

1. Pengimplementasian VoIP lebih mudah dikembangkan, karena infrastruktur jaringan yang sudah tersedia dan juga digunakannya Trixbox yang bersifat Open Source, sehingga switch yang tersedia di setiap ruangan bisa dimanfaatkan untuk jaringan VoIP.

2. Berdasarkan benefit details dari implementasi jaringan komunikasi VoIP terbukti penggunaan VoIP dapat meminimalisir biaya operasional sarana komunikasi.

\section{DAFTAR PUSTAKA}

Azhar, Badrul Akmaludin. 2018. Penerapan Voice over Internet Protokol (VoIP) Untuk Optimalisasi Jaringan Pada Badan Kependudukan Dan Keluarga Berencana Nasional. Jakarta : STMIK Nusa Mandiri Jakarta Vol.5 No.1 p-ISSN: 2406-7733 eISSN: 2597-9922.

Riswandha. 2013. Pemanfaatan Teknologi VOIP dan PABX Untuk Optimalisasi Im- 
plementasi Telepon PSTN. Bangil: STMIK Yadika Bangil. vol 18/no.1 ISSN: 1858-4667.

Yuniati,Fitriawan Patih. 2014. Analisa Perancangan Server VoIP (Voice Internet Protocol) Dengan Opensource Asterisk Dan VPN (Virtual Private Network) Sebagai
Pengaman Jaringan Antar Client. Lampung: Teknik Universitas Lampung vol 12 no. 1 ISSN : 1693-2390.

Taufiq, R. (2016). Rancang Bangun Sistem Pendukung Keputusan Hasil Nilai Siswa Naik dan Tidak Naik Berbasis Java di Sdn Sepatan II. Jurnal Teknik, 5 (2). 